\title{
ANALYZING THE TRADEOFF BETWEEN PLANNING AND EXECUTION OF ROBOTICS PROCESS AUTOMATION IMPLEMENTATION IN IT SECTOR
}

\author{
Rahul Saha ${ }^{1}$, Vikas Kulahri², Gulshan Kumar ${ }^{3 *}$, Mritunjay Kumar Rai ${ }^{4}$ \\ and Se-Jung Lim $^{5}$ \\ ${ }^{1}$ Assistant Professor, Department of Computer Science and Engineering, Lovely \\ Professional University, Punjab, India \\ ${ }^{2}$ Software Developer, Accenture, India \\ ${ }^{3}$ Assistant Professor, Department of Computer Science and Engineering, Lovely \\ Professional University, Punjab, India \\ ${ }^{4}$ Department of Electronics and Communication Engineering, Lovely Professional \\ University, Punjab, India \\ ${ }^{5}$ Department of Computer Engineering, Chonnam National University, \\ Republic of Korea \\ *gulshan3971@gmail.com
}

\begin{abstract}
We are living in the era of technology where most of the things have been digitalized. Many emerging technologies have been introduced in the market like RPA (Robotics Process Automation), AI (Artificial Intelligence) and Machine learning which are helpful to replicate the manual efforts or actions of a human being interactive with the user interface of a computer system or services. The main purpose of using such technologies is to automate the complicated processes with accurate results and reduced Fault Tolerance Error (FTE) as much as possible. However, after putting a lot effort many organizations are still not able to implement RPA successfully. It makes a tradeoff between the planning of RPA and execution of RPA which creates a loss of efforts by the companies for completing a project successfully. Therefore, in this paper, we have tried to analyze the reasons for this tradeoff and statistically the results are interpreted to identify the dominant causes of the issue.
\end{abstract}

Keywords - Robotics Process Automation, Artificial Intelligence, Fault Tolerance Error

\section{INTRODUCTION}

Robotics Process Automation (RPA) is an emerging technology with a blend of Artificial Intelligence (AI) and Machine learning. This technology enables the systems to automate the repetitive and complicated task, handle high volume data or information with higher accuracy and reduced rework. We can also consider it as a virtual 'Robot' that has replicated the manual actions of a human being interacting with user interfaces (UI) of a computer system $[1,6]$. This virtual robot works the same way a human does, automate rule-based and complex applications or websites: logging in, email extraction, operating

Received: October 16, 2018

Reviewed: December 29, 2018

Accepted: January 3, 2019

* Corresponding Author 
applications like web or desktop, entering data into ERP or SAP applications, performing complex, repetitive and logic based calculations and logging out.

According to the father of Artificial Intelligence, John McCarthy, it is "The science and engineering of making intelligent machines, especially intelligent computer programs". AI works in the same way human think and work. AI has voice recognition, machine vision and capability of self-learning and self-correction. [9] Below are few examples of AI:

- Machine Learning: It is a method of getting a computer to act without programming. There are three types of machine learning algorithms: Supervised learning, unsupervised learning and reinforcement learning. Pattern learning is the branch of machine learning which is use to work on pattern data.

- NLP (Natural Language Processing): It's the processing of human language by a computer system. For Example, Spam Detection, which looks at the subject line and an email body and decide if it's a junk. Current example of NLP is based on machine learning includes translation, analysis and speech recognition.

- Robotics: Robots are designed to preform difficult and consistently repetitive task which are quite difficult for a human. For example, Robots in car production or move large objects in space by NASA.

RPA and AI both are the part of each other. However, RPA is a rule-based automation technique and AI has the capability of self-learning. Now a days many organizations trying to replicate their manual tasks with RPA because RPA is much faster than a human-oriented process and more reliable which can reduce average handling time and also eliminates human-centric errors. As a result, processing cost is reduced significantly. Fast implementation of new processes, higher quality and re-usable process element also make the RPA acceptable and sustainable in technology trend. It also helps to save Fault Tolerance Error (FTE) and cost saving for organizations. RPA is especially useful for organizations that have many different, complicated systems that need to interact together efficiently. For Example, if a data is coming through mail and need to be posted into an ERP system and reply on the same with the confirmation. RPA task would be checking that mail because there is a fix time of receiving that mail [7]. Large and small organizations will be able to reap the benefits of RPA by expediting back-office and middle-office tasks in a wide range of industries, including banking, insurance, finance and risk, procurement, supply chain management, accounting, customer relationship management and human resource management [8]. Automation is not just about cost savings efforts - the impact is much broader for organizations. Other advantages include capacity as well as reliability and service level improvements.

\section{PRESENT INDUSTRIAL STATUS OF RPA}

RPA is quite simple and very easy to use. There is no compulsion of an IT background to be adaptive with it. It's just a drag and drop software. Once the RPA software has been trained to work on a specific task to process a certain work in existing software, [7] it can manipulate data, maintain record, calculations, queries and transactions, trigger response, start new actions and communicate with other systems. RPA can be applied to all sorts of rules-based process in a wide range of sectors, including process automation of office tasks, IT support, and assisted automation in customer service. With such a variety of areas that RPA is known to be successful in, it's no wonder that so many companies are taking advantage of the technology. RPA can be implemented in various sectors such as banking, finance, manufacturing, healthcare, logistics, consumer product, food and beverage, entertainment and many more. There are many tools available for RPA like: Automation Anywhere, UiPath, NICE, EdgeVerve, Kryon, Blue Prism. Forrester Q1'17 report [10] 
included a few RPA tools in their report based on the utilization and performance. The report has been shown in Table I.

Table I. RPA, Q1'2017 Report: Forrester

\begin{tabular}{|c|c|c|c|c|c|}
\hline $\begin{array}{c}\text { Technology } \\
\text { Category }\end{array}$ & UiPath & $\begin{array}{c}\text { Automation } \\
\text { Anywhere }\end{array}$ & NICE & EdgeVerve & Kryon \\
\hline $\begin{array}{c}\text { Bot } \\
\text { Development } \\
\text { and Core } \\
\text { Functions }\end{array}$ & 3.25 & 3.7 & 3.6 & 2.85 & 2.5 \\
\hline $\begin{array}{c}\text { Control Room, } \\
\text { System Mgmt, } \\
\text { report \& } \\
\text { resillience }\end{array}$ & 3.8 & 2.8 & 3.25 & 3.25 & 3.8 \\
\hline RPA Analytics & 3.66 & 3.66 & 2.33 & 3.34 & 2 \\
\hline Architecture & 3.99 & 4.33 & 4.33 & 3.67 & 3.66 \\
\hline $\begin{array}{c}\text { Deployment, } \\
\text { govenance and } \\
\text { security }\end{array}$ & 3.66 & 3.66 & 3.99 & 3 & 4 \\
\hline Total RPA Score & 3.672 & 3.63 & 3.5 & 3.222 & 3.192 \\
\hline
\end{tabular}

According to the Forrester report, UiPath has scored best in the terms of technology. On the other hand Automation Anywhere has grabbed the biggest market presence as compare to other tools and Blue Prism scores best in bot governance and development feature though they are a bit underrated.

RPA tools are serving various big and small organizations. We have listed some of the serviced companies in Table II.

Table II. List of companies served by RPA

\begin{tabular}{|l|l|}
\hline RPA tool & Service company \\
\hline Blue Prism: [12] & $\begin{array}{l}\text { Accenture, Capgemini, Deloitte, EY, KPMG, Symphony, } \\
\text { BNY MELLON, American Express, Prezer }\end{array}$ \\
\hline $\begin{array}{l}\text { Automation } \\
\text { Anywhere [11] }\end{array}$ & $\begin{array}{l}\text { Genpect, Wipro, Information Services Group, First Source, } \\
\text { HGC, Dell ,L \& T, KPMG, Accenture }\end{array}$ \\
\hline UiPath [3] & $\begin{array}{l}\text { NIIT, HP, Capgemini, EY, CTS, Deloitte, Atos, Mphasis, } \\
\text { Bosch }\end{array}$ \\
\hline
\end{tabular}

In this fast-growing need of RPA, each organization starves to have client and lure client by committing the targets of FTE Release. RPA is becoming a process which focus on reducing the FTE in a short period of time with automating the process. This target practicing is a major reason where the tools fail to prove the efficiency rather than eliminating the FTE. Management of the IT companies keeps on running blindly towards the goal without a thought of what went wrong and how that can be rectified. Even though the advantages of RPA are dominant in technology world [16], companies have not shifted to this paradigm of automation as they are afraid of being jobless with adapting this new technology $[13,14,15]$. 


\section{RESEARCH METHODOLOGY}

We have followed a descriptive research methodology which eventually provides the aspect of quantitative analysis. The research method followed by us is conclusive that satisfies the proper objectivity of following it. To perform this methodology, we have selected to have an online survey based primary data collection process. This primary data is unbiased and original and therefore the results interpreted with the analysis is accurate and real-environment oriented. Figure-1 shows the research methodology of our study.



Fig. 1. Research Methodology

\subsection{QUESTIONNAIRE PREPARATION}

We have generated a questionnaire to take a survey about the RPA in IT sector. The questions considered here will be stimulate the reasons in categories of technical orientation (TO), management orientation (MO) or psychological orientation (PO). This study will help us to draw the causes as per the industry parameters. The questionnaire has been provided below in Table III.

Table III. Questions for the Survey

\begin{tabular}{|l|l|l|}
\hline $\begin{array}{l}\text { Q. } \\
\text { No. }\end{array}$ & Question & Category \\
\hline 1 & Company name & NA \\
\hline 2 & Gender & PO \\
\hline 3 & Age & PO \\
\hline 4 & Designation & MO \\
\hline 5 & Working duration & MO \\
\hline 6 & $\begin{array}{l}\text { Are you aware about Automation, Artificial Intelligence and } \\
\text { Robotics ? }\end{array}$ & TO \\
\hline 7 & Is your company following automation? & MO \\
\hline
\end{tabular}




\begin{tabular}{|l|l|l|}
\hline 8 & $\begin{array}{l}\text { How many RPA oriented projects your company has done or doing } \\
\text { in last 3 years. }\end{array}$ & MO \\
\hline 9 & Which processes are followed for RPA in your company? & MO + TO \\
\hline 10 & $\begin{array}{l}\text { How many FTE are currently devoted to the activities that will be } \\
\text { performed by RPA? }\end{array}$ & MO \\
\hline 11 & $\begin{array}{l}\text { How would you describe your current awareness of Robotic } \\
\text { Process Automation (RPA) }\end{array}$ & TO \\
\hline 12 & How frequently do you use RPA tool for your process ? & TO + PO \\
\hline 13 & Your team leader or coordinator encourages for RPA ? & MO \\
\hline 14 & $\begin{array}{l}\text { How well does your leadership understand the strategic need for } \\
\text { RPA ? }\end{array}$ & MO + TO \\
\hline 15 & $\begin{array}{l}\text { How many workshops or trainings has been done regarding the } \\
\text { RPA in last 3 years. }\end{array}$ & MO \\
\hline 16 & How expensive (per head) are the staff who perform this process? & MO \\
\hline 17 & RPA Will create an overwhelming change in the industries. & PO \\
\hline 18 & Is human judgement required to perform the process ? & PO \\
\hline 19 & RPA may become a reason of being jobless in future times. & PO \\
\hline 20 & $\begin{array}{l}\text { Are you interested to shift your job profile for automation } \\
\text { processes? }\end{array}$ & PO \\
\hline
\end{tabular}

\subsection{DATA COLLECTION AND SAMPLING}

We have collected the data from the respondents through online survey from various IT companies including AB InBev, Accenture, IBM, Xorlabs, ISG, Cognizant, Pyramid solutions, HCL, RVM, TCS, Teleperformance, Automation Anywhere, Genpact, Globallogic Technologies, Acronotics, Wipro, Maersk group, Hgs, Kellton Tech, hexaware Technologies. The respondents belong from different age group with different designations and experience of work. The varsity of data has helped us to analyze it unbiased.



Fig. 2. Data encoding in SPSS of the surveyed data

After collecting the data, we have identified different variables through the questions. Total 70 responses have been accumulated. Therefore, we consider our sample size of the statistical analysis is 70 . 


\subsection{STATISTICAL ANALYSIS}

We have used SPSS-22 to analyze the collected data. We have analyzed the responses as per the following objectives.

- To analyze the behavior of the individuals towards their awareness of the RPA.

- To analyze the company behavior towards the RPA.

- To classify the dominancy of the reasons whether management, technological or psychological orientation is heavier with respect to others.

To accomplish the first objective, we have analyzed the data on the responses for the Question No. 6 and 11with respect to age and gender. We have shown the results in Figure 3 and 4.

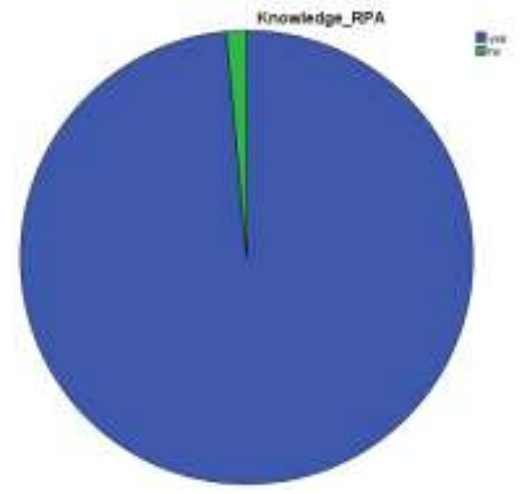

Fig. 3. Overall awareness for RPA among employees

Figure 3 signifies that the large part of the respondents (98.6\%) are well aware of the RPA. Now to further get the clarity on the responses we have categorized the responses with respect to gender and age.


Fig. 4. Awareness of RPA for individual categorized by Gender and Age

From the Figure-4 we observe that, male-female both are of the RPA significantly as their corresponding companies are using the methods of RPA. If we consider the categorization age wise, we observe that the IT employees in between age of 25-30 are more active for RPA. The reason that comes out that the individual awareness of RPA is 
created by the processes running in their respective companies but the employees are unwilling to investigate RPA further.

To analyze the second objective, first we have analyzed the responses for question no. 7. We have found that all the companies of the respondents are aware of automation. To further understand the situation, we have also analyzed question 8,9 and 10. The results are shown in Table IV, V and Vi.

Table IV. RPA Projects Count

Count

\section{Comapny_follow_automation * No_of_RPA_projects Crosstabulation}

\begin{tabular}{|c|c|c|c|c|c|}
\hline & \multicolumn{4}{|c|}{ No_of_RPA_projects } & \multirow[b]{2}{*}{ Total } \\
\hline & 0 & $1-10$ & $11-20$ & $>20$ & \\
\hline $\begin{array}{l}\text { Comapny_follow_automatio yes } \\
\text { n }\end{array}$ & 2 & 24 & 4 & 39 & 69 \\
\hline Total & 2 & 24 & 4 & 39 & 69 \\
\hline
\end{tabular}

Table V. RPA Processes Count

\begin{tabular}{|c|c|c|c|c|}
\hline \multicolumn{5}{|c|}{ Comapny_follow_automation * Processes Crosstabulation } \\
\hline & \multicolumn{3}{|c|}{ Processes } & \multirow[b]{2}{*}{ Total } \\
\hline & $\begin{array}{l}\text { Business } \\
\text { Processes }\end{array}$ & IT & $\begin{array}{c}\text { Either all or two of } \\
\text { above }\end{array}$ & \\
\hline $\begin{array}{l}\text { Comapny_follow_automation yes } \\
\text { Total }\end{array}$ & $\begin{array}{l}38 \\
38\end{array}$ & $\begin{array}{l}6 \\
6\end{array}$ & $\begin{array}{l}25 \\
25\end{array}$ & $\begin{array}{l}69 \\
69\end{array}$ \\
\hline
\end{tabular}

Table VI. FTE Count

Comapny_follow_automation * FTE number Crosstabulation

\begin{tabular}{|c|c|c|c|c|c|}
\hline & \multicolumn{4}{|c|}{ FTE number } & \multirow[b]{2}{*}{ Total } \\
\hline & $<50$ & $50-100$ & $100-200$ & $>200$ & \\
\hline Comapny_follow_automation yes & 27 & 7 & 10 & 25 & 69 \\
\hline
\end{tabular}

From the above tables, we can understand that though the companies know about RPA, but the implementation of RPA is not significant as the companies are having RPA projects but the IT processes and average FTE usage is less. This signifies that employees are not so much willing for RPA processes. 




Fig. 5. Scree plot for principal component identification

Now we wish to verify the reasons for which RPA is lagging behind in successful acceptance overall. To verify this, we have followed the principal component analysis and have found the scree-plot as shown in Figure 5. The figure shows that we can have six components for our objective as they are having the Eigen values more than 1. Depending upon this, we have the component analysis matrix as shown in Table VII.

Table VII. Component Matrix for RPA Reasons

Component Matrix ${ }^{a}$

\begin{tabular}{|c|c|c|c|c|c|c|}
\hline & \multicolumn{6}{|c|}{ Component } \\
\hline & 1 & 2 & 3 & 4 & 5 & 6 \\
\hline Understanding & .683 & & & & & \\
\hline workhop_training & .672 & & & & & \\
\hline No_of_RPA_projects & .655 & & & & & \\
\hline Encourage & -.647 & & & & & \\
\hline Awareness_individual & -.638 & & & & & \\
\hline FTE number & .614 & & & & & \\
\hline Frequency & .581 & & & & & \\
\hline Expense & .555 & & & & & .518 \\
\hline jobless_vision & & .648 & & & & \\
\hline Designation & & -.592 & & & & \\
\hline Working_span & & .540 & & & & \\
\hline Job shift & & & .666 & & & \\
\hline Processes & & .533 & .634 & & & \\
\hline RPA_change & & & & .590 & & \\
\hline Human_judgement_req & & & & & -.556 & .507 \\
\hline
\end{tabular}

From the component matrix shown in Table VII, we can deduce the components as shown in Table VIII. 
Table VIII. Deduced Principal Components

\begin{tabular}{|l|l|}
\hline Component No. & \multicolumn{1}{c|}{ Component Name } \\
\hline 1 & Management Decision \\
\hline 2 & Bounded personal perception \\
\hline 3 & Mismatch of processes and human dissatisfaction \\
\hline 4 & Motive for change \\
\hline 5 & Human judgment \\
\hline 6 & Company-employee Budget \\
\hline
\end{tabular}

\section{CONCLUSION}

It is a great thing to implement technology in the place of manual efforts just to get the better results and save money. But to make it successful, companies as leaders, must execute an extra ordinary solution or do reform and reengineer processes. From the above analysis we have found the following: first, companies are willing for RPA but falling short for expenses and training. Moreover motivation and encouraging are also strong factors. Apart from these, personal perceptions of the employees to lose job is having an effect on the issue of RPA implementation. Once we overcome these problems, we are able to adopt the new technologies with our open hand. IT industries need to believe that RPA is not to goof up the jobs, rather it will provide more job opportunities.

\section{REFERENCES}

[1] https://www.accenture.com/us-en/robotic-process-automation-software.

[2] https://www.uipath.com/automate/robotic-process-automation.

[3] www.irpaai.com/what-is-robotic-process-automation.

[4] https://www.pega.com/rpa.

[5] http://blog.symphonyhq.com/what-is-rpa.

[6] http://internetofthingsagenda.techtarget.com/definition/robotic-process-automation.

[7] http://bankingblog.accenture.com/benefits-of-robotic-process-automation-extend-beyond-just-costsavings-for-banks.

[8] http://searchcio.techtarget.com/definition/AI.

[9] Craig Le Clair, Alex Cullen, Madeline King, The Forrester Wave ${ }^{\mathrm{TM}}$ : Robotic Process Automation, Q1 2017, February, (2017).

[10] www.automationanywhere.com.

[11] https://www.blueprism.com.

[12] Hal Hodson, AI interns: Software already taking jobs from humans, The Daily Newsletter, 31 March 2015.

[13] Charlotte Jee, Technology is not about to steal your job - here's why, February, 2016 at https://www.techworld.com/careers/technology-is-not-about-steal-your-job-3634370/.

[14] Leslie Willcocks, Mary Lacity, Andrew Craig, Robotic Process Automation at Xchanging, The Outsourcing Unit Working Research Paper Series, June (2015).

[15] Robotic Process Automation Market Size, Share \& Trends Analysis Report By Services (Professional Services, Training Services), By Organization, By Application, By Region, And Segment Forecasts, 2018 - 2024, Apr, 2018, available at: https://www.grandviewresearch.com/industry-analysis/robotic-processautomation-rpa-market. 
International Journal of Control and Automation Vol. 12, No. 1 (2019) 